\title{
MECANISMOS DE TRANSFERÊNCIA DE TECNOLOGIA DO NÚCLEO DE TECNOLOGIA DA INFORMAÇÃO (NTI) PARA A REGIÃO SUDOESTE DO PARANÁ - BRASIL
}

\section{MECHANISMS OF TECHNOLOGY TRANSFER CENTER OF INFORMATION TECHNOLOGY (NTI) FOR THE SOUTHWEST REGION OF PARANA - BRAZIL}

\author{
Andriele De Prá Carvalho ${ }^{1}$; Eloiza Avila de Matos ${ }^{2}$; Dálcio Roberto dos Reis ${ }^{3}$ \\ ${ }^{1}$ Universidade Tecnológica Federal do Paraná - UTFPR - Ponta Grossa - Brasil \\ andridp@hotmail.com \\ ${ }^{2}$ Universidade Tecnológica Federal do Paraná - UTFPR - Ponta Grossa - Brasil \\ elomatos@utfpr.edu.br \\ ${ }^{3}$ Universidade Tecnológica Federal do Paraná - UTFPR - Ponta Grossa - Brasil \\ dalcio@utfpr.edu.br
}

\begin{abstract}
Resumo
Estudos teóricos sugerem que a capacidade inovadora das empresas contribui para o Desenvolvimento Regional e consequentemente para o aumento da competitividade local. Por abranger as relações entre o social, econômico, tecnológico e cultural, este estudo aponta a importância de um modelo participativo ancorado pela liderança e sociedade, em busca da disseminação e transferência do conhecimento tecnológico. Dessa forma, este artigo propôs investigar os mecanismos de Transferência de Tecnologia do APL de TI, denominado Núcleo de Tecnologia da Informação (NTI) da região Sudoeste do Paraná-Brasil, mapeando as empresas participantes, identificando esses mecanismos e analisando quais são suas influências para o Desenvolvimento Regional. A pesquisa definiu-se como qualitativa e quantitativa, e se fundamentou com base em entrevistas e análise de documentos para levantar as atividades prestadas pelo NTI e confirmar os resultados desses mecanismos de transferência de tecnologia às empresas associadas. Concluiu-se que, com os resultados apresentados e confirmados pelas empresas atuantes, os mecanismos de transferência de tecnologia disponibilizados pelo NTI contribuíram para as Inovações e conseqüentemente para o Desenvolvimento Regional.
\end{abstract}

Palavras-chave: Transferência de Tecnologia; Inovação; Desenvolvimento Regional.

\section{Introdução}

Influenciar no desenvolvimento de uma região é contribuir para que esta avance em Inovação e Tecnologia. O cenário de competitividade global traz a necessidade de gerir eficazmente os mecanismos que auxiliam para o desenvolvimento regional, pois este influenciará nos índices de desenvolvimentos de um país.

A transferência de tecnologia é um meio que auxilia no aproveitamento dos recursos e das 
potencialidades necessárias para que uma região se desenvolva, garantindo a participação dos cidadãos nesse processo.

O desenvolvimento regional parte de ações que mobilizem as empresas a buscarem no conhecimento e transferência de tecnologia as fontes necessárias para a inovação e conseqüente o crescimento sustentável.

É através da transferência de tecnologia que há um maior desenvolvimento e atuação das empresas locais. A transferência de tecnologia é o ponto de partida para que a Região conquiste inovações tecnológicas e capacidade para concorrer em novos mercados.

Dessa forma, este artigo buscou analisar os mecanismos de transferência de tecnologia no Núcleo de Tecnologia da Informação (NTI) da região Sudoeste do Paraná para identificar os fatores favoráveis ao Desenvolvimento da Região, bem como possíveis ações para incrementar esses mecanismos, podendo estas servir de base para outras regiões que busquem potencializar o seu desenvolvimento para a inovação.

\section{Referencial teórico}

\subsection{Núcleo de Tecnologia da Informação (NTI)}

O NTI ou Núcleo de Tecnologia da Informação é uma associação sem fins lucrativos que visa fomentar o desenvolvimento econômico e tecnológico de seus associados e da comunidade local envolvida, com uma proposta de divulgação planejada de todas as informações técnicas e mercadológicas da área, fomento e intercâmbio de experiências entre profissionais e empresas associadas e ações empresariais que gerem emprego e renda.

Ele iniciou através de uma proposta política em uma das cidades integrantes do APL, porém no decorrer do tempo passou a ter autonomia própria, atuando independentemente de apoio político local, e ampliando sua atuação.

O NTI resume-se como um ARRANJO PRODUTIVO LOCAL - APL da área tecnológica de TI. Este Núcleo, é o resultado do esforço de lideranças empresariais, e que conta com empresas, órgãos públicos, entidades e profissionais de TI, enfim, da comunidade local interessada em desenvolver a área de TI. Atualmente já existe o reconhecimento Estadual e Nacional dessa entidade como um dos principais atores no processo de desenvolvimento tecnológico na área de software. O NTI visa a Inovação das empresas associadas.

Sua missão é "Proporcionar a organização e aperfeiçoamento do setor de TI, buscando novas oportunidades, parcerias e políticas para atingir referência internacional."

O setor busca na transferência de tecnologia um conjunto de mecanismos necessários para o alcance de seus objetivos que são: promover treinamentos e capacitação de recursos humanos, promoção de eventos para integração e troca de experiências, trabalhar linhas de crédito exclusiva, 
criar equipe para captação de recursos, promover intercâmbio entre as empresas, criação de planos de marketing, promover seminários para inovação tecnológica, divulgar leis que regulamentem a atividade e/ou a beneficiem, apoiar e viabilizar a logística da região e definir modelo de governança.

Através dos mecanismos para transferência de tecnologia disponibilizados as 45 empresas participantes da associação, a coordenação do NTI busca contribuir para o Desenvolvimento Regional e para a competitividade local.

\subsection{O Conhecimento como base para a inovação}

A principal característica do conhecimento é a intangibilidade. Por independer de espaço, permite ao homem uma capacidade infinita de armazenamento. Ele é difusível e se autorreproduz, e é valorizado com a abundância. Está sempre em constante mutação e é extremamente sensível ao tempo (FIALHO, 2008).

Gestão do Conhecimento é o processo sistemático de identificação, criação, renovação e aplicação dos conhecimentos que são estratégicos na vida de uma organização. É a administração dos ativos de conhecimento das organizações. Nesse sentido Boog (2005, p.275) afirma:

É um desafio à nossa inteligência aprender a separar o joio do trigo, e usar o que sabemos, além de gerar informação confiável que as pessoas possam utilizar. Ao fazer isso, estamos entrando no que chamamos de gestão do conhecimento (BOOG, 2005, p.275).

A gestão do conhecimento leva as organizações a mensurar com mais segurança a sua eficiência. Leva a tomar decisões acertadas com relação à melhor estratégia a ser adotada em relação aos seus clientes, concorrentes, canais de distribuição e ciclos de vida de produtos e serviços. Leva também a saber identificar as fontes de informações; saber administrar dados e informações, gerenciar seus conhecimentos. Trata-se da prática de agregar valor à informação e de distribuí-la (DRUCKER, 2001).

Para compreender Gestão do Conhecimento, deve-se iniciar descrevendo os conceitos de dado, informação e conhecimento. Dado é o registro estruturado de transações. Genericamente, pode ser definido como um "conjunto de fatos distintos e objetivos, relativos a eventos" (DAVENPORT; PRUSAK, 2001, p. 2). É informação bruta, descrição exata de algo ou de algum evento. Os dados em si não são dotados de relevância, propósito e significado, mas são importantes porque são a matéria-prima essencial para a criação da informação. (DAVENPORT; PRUSAK, 2001).

Informação é uma mensagem com dados que fazem diferença, podendo ser audível ou visível, e onde existe um emitente e um receptor. É o insumo mais importante da produção humana. "São dados interpretados, dotados de relevância e propósito" (DRUCKER, 2001, p.32). É um fluxo 
de mensagens, um produto capaz de gerar conhecimento. É um meio ou material necessário para extrair e construir o conhecimento. Afeta o conhecimento acrescentando-lhe algo ou reestruturandoo.

O conhecimento deriva da informação assim como esta, dos dados. O conhecimento não é puro nem simples, mas é uma mistura de elementos; é fluido e formalmente estruturado; é intuitivo e, portanto, difícil de ser colocado em palavras ou de ser plenamente entendido em termos lógicos. Ele existe dentro das pessoas e por isso é complexo e imprevisível. Segundo Davenport e Prusak (2001, p. 6), "o conhecimento pode ser comparado a um sistema vivo, que cresce e se modifica à medida que interage com o meio ambiente". Os valores e as crenças integram o conhecimento, pois determinam, em grande parte, o que o conhecedor vê, absorve e conclui a partir das suas observações. Takeushi e Nonaka (2008) observam que o conhecimento, diferentemente da informação, refere-se a crenças e compromissos.

O conhecimento humano é classificado em dois tipos: conhecimento tácito e conhecimento explícito. Conhecimento explícito é o que pode ser articulado na linguagem formal, inclusive em afirmações gramaticais, expressões matemáticas, especificações, manuais etc., facilmente transmitido, sistematizado e comunicado. Já, o conhecimento tácito é difícil de ser articulado na linguagem formal, é um tipo de conhecimento mais importante. É o conhecimento pessoal incorporado à experiência individual e envolve fatores intangíveis como, por exemplo, crenças pessoais, perspectivas, sistema de valor, insights, intuições, emoções, habilidades É considerado como uma fonte importante de competitividade entre as organizações. Só pode ser avaliado por meio da ação (TAKEUCHI; NONAKA, 2008).

O conhecimento tácito e explícito são unidades estruturais básicas que se complementam e a interação entre eles é a principal dinâmica da criação do conhecimento na organização de negócios. Segundo Takeuchi e Nonaka (2008), para se tornar uma empresa que gera conhecimento (knowledge creating company) a organização deve completar uma espiral do conhecimento, espiral esta que vai de tácito para tácito, de explícito a explícito, de tácito a explícito, e finalmente, de explícito a tácito. Logo, o conhecimento deve ser articulado e então internalizado para tornar-se parte da base de conhecimento de cada pessoa.

A espiral começa novamente depois de ter sido completada, porém em patamares cada vez mais elevados, ampliando assim a aplicação do conhecimento em outras áreas da organização. A gestão do conhecimento é um processo corporativo, focado na estratégia empresarial e que envolve a gestão das competências, a gestão do capital intelectual, a aprendizagem organizacional, a inteligência empresarial e a educação corporativa (SENGE; CARSTEDT, 2001).

A Gestão do Conhecimento envolve as Competências por englobar o conhecimento real, a habilidade, a experiência, os julgamentos de valor e redes sociais, sendo o elo entre conhecimento e 
estratégia. As competências não podem ser copiadas com exatidão, são transferidas pela prática. A Gestão do Conhecimento engloba também o Capital Intelectual que é a soma do conhecimento de todos em uma organização, o que lhe proporciona vantagens competitivas; sendo a capacidade mental coletiva, a capacidade de criar continuamente e proporcionar valor de qualidade superior (RICHARD, 2003).

O conhecimento organizacional pode também ser desenvolvido na aprendizagem organizacional através de um processo contínuo de detectar e corrigir erros. Errar significa aprender, envolvendo a autocrítica, a avaliação de riscos, a tolerância ao fracasso e a correção de rumo, até alcançar os objetivos. A aprendizagem Organizacional é a capacidade das organizações em criar, adquirir e transferir conhecimentos e em modificar seus comportamentos para refleti-los em novos conhecimentos e insights, conforme (SENGE; CARSTEDT, 2001).

Nesse contexto a Inteligência Empresarial, que é a capacidade de desenvolvimento da aprendizagem, auxilia na gestão do conhecimento por ser um programa sistemático para coleta e análise de informações sobre as atividades de concorrentes e tendências dos negócios a fim de alcançar os objetivos da organização, dito de outra forma, é uma coleção de peças de informação que são filtradas, destiladas e analisadas e que constituem o que os dirigentes realmente necessitam para a tomada de decisão, de modo a detectar e avaliar oportunidades e ameaças do mercado (RICHARD, 2003) .

Cria-se assim, vantagem competitiva para a empresa, a implementação de um ambiente para o desenvolvimento da capacidade de aprendizado da organização, criando situações que permitam a discussão de problemas comuns e soluções por meio da aprendizagem coletiva (RICHARD, 2003).

\subsection{Produção e transferência do conhecimento}

O processo de transferência envolve diferentes formas de transmissão de conhecimentos, incluindo: contrato de assistência técnica, em que a empresa obtém ajuda externa para iniciar o processo produtivo, solucionar problemas ou lançar novos produtos, licenças para utilização de marca registrada, aquisição de serviços, entre outros (REIS, 2008).

As organizações que buscam a competitividade, notaram que a gestão do conhecimento, introduz um suporte para seu crescimento. Fleury (2002) expõe a necessidade de práticas organizacionais que permitam as pessoas produzirem e transferirem o conhecimento. Pois a sociedade atual está voltada ao conhecimento, sendo que a criação, a manutenção e a distribuição da informação constituem a maior forma de riqueza e competitividade das empresas (LOURES; SCHLEMM, 2006).

Para que ocorra a transferência de tecnologia, o aprendizado contínuo no ambiente de trabalho é essencial. Esse aprendizado orienta os integrantes da organização através das 
informações repassadas em assembléias de usuários muito mais do que em coleção de livros ou outros documentos (FONSECA, 1998). Intensifica-se assim, a importância do ambiente organizacional na produção de conhecimento e repasse do mesmo. O processo de inovação se dá por intermédio da gestão do conhecimento, e esta caracteriza o capital intelectual que possui poder econômico bem mais representativo que ativos imobilizados (REIS, 2008).

Dessa forma, o conhecimento na sociedade atual pode ser considerado como essencial para o desenvolvimento das organizações, sendo o conhecimento o recurso mais valioso nas diversas áreas de atuação, pelo fato de interligar a transferência do conhecimento com as inovações (ANDRADE; RODRIGUES, 2008).

O cenário atual, no qual se encontram as empresas, impõe a necessidade de obter e selecionar as informações advindas (ALPERSTEDT, 2002). Nesse sentido, o conhecimento é um dos recursos mais extraordinários para a empresa, trazendo vantagens competitivas que possibilitarão selecionar as informações. Reis (2008, p.3) afirma: “é necessário examinar realmente os mecanismos e processos pelos quais o conhecimento é criado, transferido e gerenciado.”

Pode-se então definir, segundo Loures e Schlemm (2006, p.45), que a sociedade do conhecimento "se sustenta nos conceitos de educação continuada ou ao longo da vida, trabalhadores aprendizes e organizações que aprendem.”

Ressalta assim, os conceitos de Eboli (2002) que ao gerir e transferir conhecimento na empresa surge o processo de transferência deste saber, sobre o qual a empresa pode ter influência, sendo que os principais desafios impostos pela empresa podem ser definidos como:

Aprender a lidar com a rápida obsolescência do conhecimento; incorporar ritmo, rapidez e precisão nas informações; compreender que é necessário a conexão entre conhecimentos já existentes; descobrir as formas pela qual a aprendizagem pode ser estimulada; ampliar a rede de relacionamentos internos e externos da organização.

A produção e a transferência do conhecimento organizacional conduz ao alcance do sucesso esperado pela organização, por estimular o aprendizado contínuo e inovador (EBOLI, 2002).

\subsection{Transferência de tecnologia}

O desenvolvimento tecnológico é resultado da competitividade que repercute no cenário econômico, no qual uma organização passa a ser considerada como desatualizada se não acompanhar essa era do conhecimento. Allarakhia e Walsh (2011) afirmam: “ o desenvolvimento tecnológico é cada vez mais impulsionado pelo avanço do mercado.”

O fator tecnologia que no conceito de Reis (2004) corresponde a um acervo de conhecimento de uma sociedade fundamentada nos métodos e conhecimentos científicos, estabelecendo domínio dos materiais e processos úteis à produção, passou a entrar em cena como 
fator relevante. As organizações priorizam o acesso a tecnologia, e os mecanismos para sua transferência, incrementa o potencial inovador.

Essa transferência de tecnologia compreende introduzir uma nova tecnologia ou os conhecimentos vinculados a ela em um ambiente diferente do qual a gerou, ou a transferência de tecnologia pode ser referir a importação de tecnologia (LIMA, 2004).

A metodologia para essa transferência é fundamental para repasse da inovação que cria vantagem competitiva substituindo as tecnologias existentes. Pois uma das complexidades na transferência de tecnologia é a forma como esta é percebida através do seu produto ou processo.

Para que o sucesso nos mecanismos de transferência de tecnologia obtenham sucesso é importante a participação do governo neste processo, na busca de uma conscientização cultural e econômica. Essa conscientização torna-se o diferencial na difusão da tecnologia pois esta implica na troca de informações de forma a favorecer todos os envolvidos.

O processo de transferência de tecnologia segue algumas etapas. A primeira etapa é a identificação da tecnologia a ser transferida, sendo seguido da seleção dos métodos que a adotarão e os mecanismos de transferência. Logo, segue-se a implementação e absorção da inovação. A quantidade de capacidade tecnológica repassada dependerá dos mecanismos escolhidos para o processo, demonstrando estes serem de suma importância a efetivação da inovação.

\subsection{Desenvolvimento regional}

O espaço regional pode ser definido como local onde ocorrem as relações entre o social, econômico e cultural, sendo estes vivenciados em constantes mudanças que ocorrem de forma acelerada. Por isso, Veiga (2006) aponta a necessidade de um modelo participativo de planejamento deste desenvolvimento, pois a região está no centro das estratégias que visam à competitividade e atratividade econômica e esta pode ser gerada com a participação popular, ancoradas as instituições locais e lideranças da sociedade.

O desenvolvimento regional deve partir de pontos que traduzem na aplicação de um planejamento, visando torná-la sustentável (VEIGA, 2006). Sendo que um planejamento regional sustentável requer um grau de capacitação tecnológica dos agentes envolvidos, sendo que um dos principais fatores que diferem os desenvolvimentos das regiões é o fator inovação.

Essa noção de que a capacidade inovadora das empresas é influenciada por fatores regionais, tornou interessante a sua análise. Rocha e Dufloth (2009) descrevem que diferenças regionais nos níveis de atividade de inovação podem ser substanciais, e identificar as principais características e fatores que promovem a atividade de inovação e o desenvolvimento de setores específicos no âmbito regional pode auxiliar o entendimento dos processos de inovação e ser válido para a elaboração de políticas. Esses sistemas regionais de inovação podem desenvolver-se paralelamente 
aos nacionais.

O manual de Oslo, na sua terceira edição, também indica a necessidade e importância de elaborar indicadores que reflitam os sistemas de inovação subnacional (regional).

Nesse sentido, podemos verificar a necessidade de buscar dados que mensurem a inovação na região de Francisco Beltrão, pois não existe nenhuma pesquisa ou dados levantados até o momento.

\subsection{Transferência de tecnologia e inovação: bases para o desenvolvimento regional}

Um dos caminhos para o avanço em inovação e tecnologia deve partir do desenvolvimento das regiões, pois estas servirão de base para o resultado final em inovação de um país inteiro, pois esses sistemas regionais de inovação podem desenvolver-se paralelamente aos nacionais.

Veiga (2006) expõe a importância do desenvolvimento regional como ponto de partida para aplicação de uma cultura voltada a inovação. A cultura de uma região é fator fundamental para a transferência de Tecnologia, pois pode tornar-se uma barreira. (BJERREGAARD, 2010, p. 106).

O desenvolvimento regional busca fontes de conhecimento nas capacidades inovadoras e tecnológicas, principalmente advindas das empresas. É através desse conhecimento organizacional que ocorre a transferência de tecnologia, e independente da maneira como este é transferido, só apresentará eficácia se este processo de transferência de tecnologia estiver intimamente ligado a aprendizagem organizacional (LIU; TANG; ZHU, 2008).

Devido essa grande importância da transferência de tecnologia para gerar novos conhecimentos, inovação, e conduzir ao desenvolvimento regional, ela torna-se um desafio, tanto pra os países desenvolvidos como para os países em desenvolvimento. (LIU; TANG; ZHU, 2008). Visualiza-se na transferência de tecnologia fatores incondicionais para a inovação, pois esta: “é importante em todas as economias, porque gera conhecimento, e este conhecimento gera mais inovação.” (BAS; AMOROS; KUNC, 2008, p.53).

Em decorrência do avanço da ciência e tecnologia e a crescente globalização, a transferência de tecnologia alia-se a inovação que tem experimentado uma mudança notável nos últimos anos (MOLERO; GARCIA, 2008). “A transferência de tecnologia se torna uma ferramenta eficaz para que empresas ou países adquiram as tecnologias necessárias para o seu desenvolvimento" (JR; PIO; ANTUNES, 2009, p.126).

É através da transferência de tecnologia que pode ser estimulada a consolidação de empresas regionais inovadoras, que busquem a competitividade a nível global, buscando na inovação vantagens competitivas (ROBERTSON; SORBELLE; UNSWORTH, 2009, p. 2).

Essa noção de que a capacidade inovadora das empresas é influenciada por fatores regionais, tornou interessante a sua análise. Rocha e Dufloth (2009) descrevem que diferenças 
regionais nos níveis de atividade de transferência de tecnologia podem ser substanciais para a inovação e competitividade. Identificar as principais características e fatores que promovem a atividade de transferência de tecnologia e o desenvolvimento de setores específicos no âmbito regional pode auxiliar o entendimento dos processos de inovação e ser válido para a elaboração de políticas e mecanismos (ECKER et al., 2003).

Nessa incessante busca por políticas e mecanismos que incentivem a inovação e pesquisas tecnológicas, a transferência de tecnologia torna-se relevante, principalmente por meio do estabelecimento de parcerias entre empresas ou grupo de empresas através do incentivo público a formulação e implementação de políticas que priorizem a transferência de tecnologias visando o desenvolvimento local (JUNIOR; PIO; ANTUNES, 2009, p.126).

Esse apoio público no que se refere a formação de parcerias entre empresas prioriza a transferência de tecnologia, devido ao fato de que além da necessidade do repasse dos conhecimentos, para que ela aconteça, é fundamental que o receptor esteja no mesmo patamar de capacitação tecnológica (PLONSKI, 2005). Sendo este um passo para a verdadeira acepção da transferência de tecnologia que necessita: a absorção do conhecimento, a adaptação, o aperfeiçoamento, a inovação e a difusão (LONG, 1984).

Mecanismos públicos para aperfeiçoar a capacitação e aumentar o nível de repasse e internalização das tecnologias, tornando um grupo de empresas aptas a esta disseminação do conhecimento, garante que os resultados serão favoráveis ao desenvolvimento (PLONSKI, 2005).

As tecnologias são interdependentes entre si, e o seu repasse deve focalizar as tecnologias correlatas ou paralelas para que não tornar inviável qualquer esforço de transferência.

É demonstrado então, que não basta aderir a uma nova tecnologia, é preciso saber geri-la, para não tornar parcial e limitada a transferência da tecnologia, fundamental para o avanço ao desenvolvimento regional.

Esse desenvolvimento de uma dada região é fundamental e se mostrará cada vez mais necessário para que o país atinja seu desenvolvimento fundamental.

\section{Metodologia}

A pesquisa classifica-se como exploratória e descritiva. Exploratória por explorar uma dada região e descritiva por descrever os processos e resultados com a aplicação dos mecanismos de transferência de tecnologia. Também se classifica como qualitativa e quantitativa. Qualitativa por analisa as opiniões e dadeos levantado e quantitativa por analisar dados numéricos, e dessa forma analisar quais os mecanismos utilizados pelas empresas e identificar os reais impactos que estes geram.

O estudo se fundamentará com base em entrevistas e análise de documentos para levantar as 
atividades prestadas pelo NTI e confirmar se os resultados desses mecanismos de transferência de tecnologia contribuem ao desenvolvimento regional.

Primeiramente foram realizadas análise de documentos e entrevista aos coordenadores do NTI para verificar quais dos mecanismos de transferência de tecnologia objetivados pela organização são aplicados às empresas participantes, e quais os resultados e melhorias a partir dessas ações.

Após identificação dos mecanismos, ações e resultados esperados, foram aplicadas entrevistas as 45 empresas associadas, seguindo um roteiro contemplando as afirmações dos coordenadores do NTI para confirmar se os mecanismos de transferência de Tecnologia são realmente aplicados, e se trazem melhorias para seu desenvolvimento como organização e consequentemente ao desenvolvimento regional.

\section{Resultados e discussões}

Tendo em vista a entrevista aplicada aos coordenadores do NTI, foi possível levantar um total de dez mecanismos de transferência de tecnologia, que de acordo com os mesmos, seriam utilizados nas 43 empresas associadas. Esses mecanismos podem ser visualizados conforme quadro 1.

\begin{tabular}{|r|l|}
\multicolumn{1}{l}{ Quadro 1 - Mecanismos de Transferência de Tecnologia do NTI } \\
\hline 1 & Treinamentos e capacitação de RH \\
\hline 2 & Promoção para eventos de integração \\
\hline 3 & Qualificação para captação de recursos \\
\hline 4 & Promoção de intercâmbio entre as empresas \\
\hline 5 & Promoção de seminários para inovações tecnológicas \\
\hline 6 & Conhecimentos das leis incidentes e políticas públicas \\
\hline 7 & Apoio a logística da região \\
\hline 8 & Divulgar o APL através de um plano de marketing \\
\hline 9 & Estabelecimento de um laboratório tecnológico regional \\
\hline 10 & Estabelecer um modelo de governança \\
\hline
\end{tabular}

Fonte: Próprio autor

Com base nesses 10 mecanismos relatados em entrevista, os coordenadores do NTI, acreditam que expressam ações positivas para o desenvolvimento das organizações associadas e consequentemente da região abrangida. Fiates et al. (2002) relata que através da transferência de tecnologia ocorre a aprendizagem e a aplicação de práticas de sucesso, implementando a inovação. E a capacidade para a aprendizagem é um fator crítico para a inovação (GUO; GUO, 2011).

Segundo os entrevistados esses mecanismos garantem a base necessária para a transferência de tecnologia e conseqüente troca de conhecimento, gerando novos conhecimentos 
que levariam a inovação. Este agrupamento de empresas com objetivo comum, que é o desenvolvimento e a inovação, segundo HU (2007) estimula a transferência de tecnologia.

Com relação à acessibilidade aos mecanismos, os coordenadores relataram que poderá ocorrer a qualquer momento, desde que o benefício buscado esteja disponível, como por exemplo, foi relatado o mecanismo treinamento e capacitação de Recursos Humanos, pois é necessário que um programa de treinamento esteja sendo implantado, para assim ser utilizado. Barbieri (1990) reforça a importância que em cadeia produtiva uma empresa deve auxiliar as demais através do repasse de informações.

As empresas associadas podem manter-se atualizadas com as ações desenvolvidas pela NTI através das reuniões mensais, e via e-mail ou correspondências. A reunião é realizada cada vez em uma diferente cidade da Região, para facilitar o acesso a todos. Os custos com deslocamentos são restituídos pela própria associação, garantindo a participação de $100 \%$ das empresas. De acordo com Matos (2002) a força motriz de um sistema motivado pela inovação tecnológica pode ser a transferência de tecnologia.

Segue abaixo, no quadro 2, alguns resultados relatados pelos coordenadores do NTI e pesquisados em documentos da Associação, que serviram de base para o questionário aos gestores das empresas associadas.

Quadro 2 - Resultados relatados e coletados com base no NTI

\begin{tabular}{|l|}
\multicolumn{1}{|c|}{ Resultado } \\
\hline Treinamentos em 70\% das empresas \\
\hline Participação de $80 \%$ das empresas em eventos para divulgação \\
\hline Divulgação da região \\
\hline $\begin{array}{l}\text { Conquista de apoio e incentivo do governo municipal para o } \\
\text { avanço da Inovação Tecnológica }\end{array}$ \\
\hline $\begin{array}{l}\text { Envolvimento de empresas, entidades de ensino, créditos, } \\
\text { governamentais e não-governamentais }\end{array}$ \\
\hline 10 patentes registradas \\
\hline Inovação presente em 60 \% das empresas envolvidas \\
\hline 10 projetos encaminhados ao governo \\
\hline $\begin{array}{l}\text { Contribuição a outros segmentos da região que necessitam da } \\
\text { Tecnologia da Informação }\end{array}$ \\
\hline Criação e apresentação de Leis direcionadas a Inovação \\
\hline Avanço no desenvolvimento das empresas envolvidas \\
Fonte: próprio autor
\end{tabular}

De acordo com o quadro visualiza-se que o NTI acredita contribuir com o avanço das empresas envolvidas e da região como um todo, disseminando a importância da transferência de tecnologia para a Inovação, sendo este o ponto forte desta associação. Matos (2002) cita que Os avanços contínuos na informática e na tecnologia de informação estão na vanguarda da onda atual de inovação de alta tecnologia.

Quanto às barreiras descritas pelos gestores do NTI, a maior ficou definida como a dificuldade em disseminar e caracterizar a Inovação, pois a partir da reflexão do seu conceito e sua 
importância é que as empresas focarão melhor a importância da transferência de tecnologia e da NTI.

Frente a estes resultados direcionados aos diretores do NTI, foi apresentado às empresas participantes os dados recolhidos para verificar se estas compartilhavam das mesmas informações e concordavam com os mecanismos de transferência de tecnologia e os resultados citados.

A tabela 3 apresenta os resultados da porcentagem do total de 45 empresas que concordam com os mecanismos de transferência de tecnologia citados pelos gestores do NTI como disponíveis e aplicáveis.

Quadro 3 - Porcentagem de empresas que concordam com os mecanismos de transferência de tecnologia citados pelo NTI

\begin{tabular}{|r|lc}
\hline 1 & Treinamentos e capacitação de RH & $85 \%$ \\
\hline 2 & Promoção para eventos de integração & $80 \%$ \\
\hline 3 & Qualificação para captação de recursos & $75 \%$ \\
\hline 4 & Promoção de intercâmbio entre as empresas & $80 \%$ \\
\hline 5 & Promoção de seminários para inovações tecnológicas & $80 \%$ \\
\hline 6 & Conhecimentos das leis incidentes e políticas públicas & $80 \%$ \\
\hline 7 & Apoio a logística da região & $90 \%$ \\
\hline 8 & Divulgar o APL através de um plano de marketing & $90 \%$ \\
\hline 9 & Estabelecimento de um laboratório tecnológico regional & $65 \%$ \\
\hline 10 & Estabelecer um modelo de governança & $80 \%$ \\
\hline
\end{tabular}

Fonte: próprio autor

Do total das empresas participantes do APL, pode-se analisar que grande parte delas concordam com os mecanismos de transferência de tecnologia citados como disponíveis pelos coordenadores do APL. Os determinantes que atingiram um maior grau de concordância foram: Divulgar o APL através de um plano de Marketing e Apoio logístico a região, com 90\% das empresas de acordo. Esse apoio logístico a região é embasado principalmente pela abertura do aeroporto na cidade de Francisco Beltrão, pertecente ao APL.

Os mecanismos de transferência de tecnologia que obtiveram menor aprovação foram qualificação para captação de recursos com $75 \%$, e estabelecimento de um laboratório tecnológico regional com $65 \%$, isto deve-se ao fato de ainda estar apenas em projeto o laboratório tecnológico regional, ou seja, isto demonstra que mesmo ainda em projeto as empresas possuem credibilidade no núcleo, quanto a execução deste mecanismo.

De uma maneira geral, todos os mecanismos de transferência de tecnologia citados pelos coordenadores do NTI obtiveram a maioria da aprovação das empresas participantes deste APL, demonstrando que este mecanismos são realmente disponibilizados.

Com relação aos resultados citados pelos coordenadores do NTI, buscou-se verificar qual o 
grau de concordância das empresas a cada um deste fator, seguindo na tabela 4.

Quadro 4- Porcentagem das empresas que concordam com os resultados relatados e coletados com base no
\begin{tabular}{|l|c|}
\hline \multicolumn{1}{|c|}{ Resultado } & Porcentagem \\
\hline Treinamentos em 70\% das empresas & $95 \%$ \\
\hline Participação de 80\% das empresas em eventos para divulgação & $95 \%$ \\
\hline Divulgação da região & $100 \%$ \\
\hline $\begin{array}{l}\text { Conquista de apoio e incentivo do governo municipal para o avanço da } \\
\text { Inovação Tecnológica }\end{array}$ & $90 \%$ \\
\hline $\begin{array}{l}\text { Envolvimento de empresas, entidades de ensino, créditos, governamentais e } \\
\text { não-governamentais }\end{array}$ & $90 \%$ \\
\hline 10 patentes registradas & $95 \%$ \\
\hline Inovação presente em 60 \% das empresas envolvidas & $95 \%$ \\
\hline 10 projetos encaminhados ao governo & $95 \%$ \\
\hline $\begin{array}{l}\text { Contribuição a outros segmentos da região que necessitam da Tecnologia da } \\
\text { Informação }\end{array}$ & $90 \%$ \\
\hline Criação e apresentação de Leis direcionadas a Inovação & $90 \%$ \\
\hline Avanço no desenvolvimento das empresas envolvidas & $90 \%$ \\
\hline
\end{tabular}

Fonte: próprio autor

Este grau de concordância ficou alto, ou seja, as empresas realmente concordam com os resultados disponibilizados através dos mecanismos de transferência de tecnologia, obtendo de $90 \%$ a $100 \%$ de aprovação. $\quad$ Este resultado indica a autonomia e capacidade do NTI para Inovação e o Desenvolvimento da Região.

\section{Considerações finais}

Ao decorrer deste trabalho é possível analisar a importância dos mecanismos de transferência de tecnologia para o Desenvolvimento Regional. A partir da iniciativa e organização de um APL em TI, houve um maior envolvimento e atuação das empresas locais, e através da transferência de tecnologia o ponto de partida para as inovações.

Nesse sentido, com os resultados apresentados e confirmados pelas empresas atuantes os mecanismos de transferência de tecnologia disponibilizados pelo NTI contribuíram para as Inovações e conseqüentemente para o Desenvolvimento Regional.

\section{Abstract}

Theoretical studies suggests that the innovative capacity of companies contributes to regional development and consequently to increase local competitiveness. Covering the relationships among the social, economic, technological and cultural, this study highlights the importance of a participative system grounded on the leadership and society in search of dissemination and technologic transfer knowledge. By this way, this article aims to investigate the technology transfer mechanisms of APL (Brazilian acronym for "Arranjo Produtivo Local") for IT, called the Center for Information Technology, or NTI (Brazilian acronym for "Núcleo de Tecnologia da Informação") in the southwestern region of Parana, Brazil, mapping the participating companies, identifying and analyzing these mechanisms and their influences on Regional Development. The research was defined as qualitative and quantitative, and was based on interviews and document analysis to raise the activities provided by the NTI and confirm the results of these mechanisms in order to transfer technology to member companies. It was concluded that, with the results presented 
and confirmed by the acting companies, the mechanisms of technology transfer offered by NTI contributed to the innovations and therefore for regional development.

Key-words: technology transfer; innovation; regional development.

\section{Referências}

ALLARAKHIA, M.; WALSH, S. Managing knowledge assets under conditions of radical change: the case of the pharmaceutical industry (2011). TECHNOVATION, 31, 2011, 105-117.

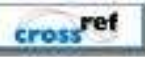

ALPERSTEDT, C. Universidades Corporativas: discussão e proposta de uma definição. Revista de Administração Contemporânea. Curitiba Set./Dez 2002 v. 5 n³

ANDRADE, R. J. F.; RODRIGUES, M. V. R. Educação Corporativa: Prática de Treinamento na Sociedade do Conhecimento. IV Congresso Nacional de Excelência em Gestão, 4, jul / ago 2008, Niterói-RJ. Anais... Niterói: CNEG, 2008.

BARBIERI, JC Production and technology transfer. New York: Attica, 1990.

cross ref

BAS, T. G.; AMOROS, E.; KUNC, M. (2008). Innovation, Entrepreneurship and Clusters in Latin America Natural Resource - implication and Future Challenges. Journal of Technology Management \& Innovation, 52-65, 2008.

BJERREGAARD, T. Industry and academia in convergence: Micro-institutional dimensions of R \& D collaboration. Technovation, 30, 100-108, 2010.

BOOG, G. Manual de gestão de pessoas e equipes. v.2 São Paulo: Gente, 2005.

DAVENPORT, T. H.; PRUSAK, L. Conhecimento empresarial: como as organizações gerenciam o seu capital intelectual. 3 ed. Rio de Janeiro: Campus, 2001.

DRUCKER, P. F. Inovação e espírito inovador. São Paulo, SP: Thompson, 2001.

EBOLI, M. O desenvolvimento das pessoas e a gestão corporativa. In: Marisa Eboli (Org.). As pessoas na organização. São Paulo: Editora Gente, 2002, v. 01, p. 185-200.

ECKER, A. et al.. Production of ceramic white table and decoration and design of wide field: a study on the situation of micro, small and medium industries and the possibility of developing sector through the design. research report. Curitiba: UFPR, 2003.

FLEURY, M. T. L. A gestão de competência e a estratégia organizacional. In: Maria Tereza Leme Fleury. (Org.). As pessoas na organização. São Paulo: Editora Gente, 2002, v. 01, p. 51-61.

FIALHO, F. Gestão da sustentabilidade na era do conhecimento. Florianópolis: Visual books, 2008.

FIAT, J. E. A. (Coord.) et al.. Glossary of terms in the dynamic area of technopolis, technology parks and incubators. Brasília: ANPROTEC / SEBRAE, 2002. 124 p.

FONSECA, E. N. D. “Um novo conceito de biblioteca e uma nova missão para o bibliotecário”. Em seu: Problemas brasileiros de documentação. Brasília: IBICT, 1998, p. 152-157.

GUO, B.; GUO, Jing-Jing. (2011). Patterns of technological learning Within the knowledge systems of industrial clusters in Emerging Economies: Evidence from China. Technovation, 31 87-104.

\section{cross ref}

Hu, A. G. Technology parks and regional economic growth in China. Research Policy 36. 2007 p. 76-87.

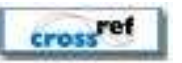


JUNIOR, E. B.; PIO, M.; ANTUNES, A. (2009). The Process of Technology Transfer in the Textile Industry. Journal of Technology Management \& Innovation, 125-133.

LIMA, G. F. C. Educação ambiental crítica: do socioambientalismo às sociedades sustentáveis. Educação e Pesquisa, São Paulo, v.35, n.1, p. 145-163, jan/abr. 2009.

LIU, B.; TANG, N.; ZHU, N. Transferring technology across borders: institutional effects in Chinese context. The Journal of Technology Transfer. 33, 619-630.

cross ref

LONG, W. P. Technology and National_Sovereignty. São Paulo - SP: Nobel, 1984.

LOURES, R. C. R.; SCHLEMM, M. M. Inovação em ambientes organizacionais: teorias, reflexões e práticas.

Curitiba: Ibpex, 2006.

MATOS, E. A. A. O processo de transferência entre universidade-empresa: uma proposta de metodologia de negociação. Dissertação. (Programa de Pós- Graduação em Tecnologia) - Universidade Tecnológica Federal do Paraná. 2002.

MELO P. A. A cooperação universidade/empresa nas universidades públicas brasileiras. Tese. (Programa de PósGraduação em Engenharia de Produção) - Universidade Federal de Santa Catarina. Florianópolis. Outubro, 2002.

MOLERO, J.; GARCIA, A. (2008). The Innovative activity of foreign Subsidiaries in the Spanish Innovation System: An evaluation of Their impact from a sectoral taxonomy approach. Technovation, 28, 739-757, 2008.

crossef

PLONSKI, G. A. Grounds for a motion by technological innovation in Brazil. São Paulo. Perspec. [Online]. 2005, vol.19, n.1, pp. 25-33. ISSN 0102-8839.

REIS, D. R. Gestão da Inovação Tecnológica. 2 ed. São Paulo: Manole, 2008.

RICHARD, G. Os Segredos da Cultura Empresarial: Como entender a alma das Culturas Organizacionais bem sucedidas. Rio de Janeiro: Campus, 2003.

ROBERTSON, J.; SORBELLO, T.; UNSWORTH, K.. (2009). Innovation implementation: the role of technology diffusion agencies. Journal of Technology Management \& Innovation, 1-10, 2009.

ROCHA, M. P. ; DUFLOTH, S. C. Análise comparativa regional de indicadores de inovação tecnológica empresarial: contribuição a partir dos dados da pesquisa industrial de inovação tecnológica. Revista Perspectiva em Ciência da Informação, v.4, n.1, p.192-208, jan./abr. 2009.

SENGE, P. M.; CARSEDT, G. Rumo à próxima revolução. Revista HSM Management, São Paulo, v.5, n.27, p.120128, jul./ago. 2001.

TAKEUCHI, H. ; NONAKA, I. Gestão do Conhecimento. Artmed, 2008.

TAKAHASHI, V. P. Knowledge Transfer Technology: Multiple Case Study of the Pharmaceutical Industry. Management \& Production Magazine,UFSCar, v. 12, n. May-August, p. 255-269, 2005.

VEIGA, J. E. Territórios para um desenvolvimento sustentável. Territórios, Ciência \& Cultura, n. 58, jan./mar. São Paulo: 2006.

\section{Dados dos autores:}

\section{Nome completo: Andriele De Prá Carvalho}

Filiação institucional: Universidade Tecnológica Federal do Paraná (UTFPR)

Departamento: Programa de Pós-Graduação em Engenharia de Produção 
Função ou cargo ocupado: Mestrando

Endereço: Av. Monteiro Lobato, s/n Km 04, Ponta Grossa - PR, CEP: 84.016-210, Brasil.

Telefones para contato: (46) 84072047

e-mail: andridp@hotmail.com

Nome completo: Eloiza Avila de Matos

Filiação institucional: Universidade Tecnológica Federal do Paraná (UTFPR)

Departamento: Programa de Pós-Graduação em Engenharia de Produção

Função ou cargo ocupado: Professor

Endereço: Av. Monteiro Lobato, s/n Km 04, Ponta Grossa - PR, CEP: 84.016-210, Brasil.

Telefones para contato: (42) 32204800

e-mail:elomatos@utfpr.edu.br

Nome completo: Dálcio Roberto dos Reis

Filiação institucional: Universidade Tecnológica Federal do Paraná (UTFPR)

Departamento: Programa de Pós-Graduação em Engenharia de Produção

Função ou cargo ocupado: Professor

Endereço: Av. Monteiro Lobato, s/n Km 04, Ponta Grossa - PR, CEP: 84.016-210, Brasil.

Telefones para contato: (42) 32204800

e-mail:dalcio@utfpr.edu.br

Enviado em: 23/04/2011

Aprovado em: 07/12/2011 